\title{
Risk Factors of Stroke in Pakistan: A Dedicated Stroke Clinic Experience
}

\author{
Fawad Taj, Rehan Zahid, Umm-e-Rubab Syeda, Muhammed Murtaza, \\ Shahzad Ahmed, Ayeesha Kamran Kamal
}

\begin{abstract}
Background: Secondary prevention of cerebrovascular disease through dedicated stroke clinics has been shown to decrease recurrent vascular events in patients. However, there is limited literature describing such stroke clinic experiences from low and middle income countries. This study describes patient characteristics and observations made at the first systematized stroke clinic in Pakistan. Methods: A retrospective audit of medical records of all patients presenting between September 2006 and August 2008 with a cerebrovascular event was conducted. Information about clinical presentation, modifiable risk factors and laboratory and radiological investigations was collected. Burden of disability was assessed using Modified Rankin score. Data was entered and analyzed using SPSS 14.0. Results: 159 patients with a mean age of $57.0 \pm 13.9$ years were included in this study and $34.6 \%$ of all patients were women. 108 patients were diagnosed with ischemic stroke $(67.9 \%)$ while 34 patients presented with hemorrhagic stroke (21.4\%) and 17 patients presented with transient ischemic attacks (10.7\%). Hypertension was the most common modifiable risk factor seen in $78.0 \%$, followed by diabetes in $40.3 \%$ and dyslipidemia in $31.5 \%$. At presentation to clinic, only $26.0 \%$ patients with dyslipidemia and $64.5 \%$ patients with hypertension were on appropriate medications. Conclusion: A high prevalence of modifiable risk factors such as hypertension in stroke patients was observed and it presents an opportunity for conventional interventions in Pakistan. Systematized clinics for stroke and an algorithmic approach in primary care towards stroke may improve the implementation of evidence based secondary prevention strategies in developing countries.
\end{abstract}

RÉSUMÉ: Facteurs de risque de l'accident vasculaire cérébral au Pakistan : l'expérience d'une clinique spécialisée. Contexte : Il est bien établi que la prévention secondaire de la maladie cérébrovasculaire dans des cliniques spécialisées en AVC diminue le taux de récidive chez ces patients. Cependant, il y a peu de publications sur ce type de cliniques établies dans des pays à moyen ou à faible revenu. Cette étude décrit les caractéristiques et les observations de patients de la première clinique spécialisée en AVC au Pakistan. Méthodes : Nous avons effectué une revue rétrospective des dossiers médicaux de tous les patients qui ont consulté à la clinique entre septembre 2006 et août 2008 pour un événement cérébrovasculaire. L'information au sujet du tableau clinique, des facteurs de risque modifiables et des examens de laboratoire et de radiologie a été colligée. Le niveau d'invalidité a été évalué au moyen du score à l'échelle de Rankin modifiée. Les données ont été analysées au moyen de SPSS 14.0. Résultats : Cent cinquante-neuf patients, dont l'âge moyen était de 57,0 \pm 13,9 ans et dont 34,6\% étaient des femmes, ont été inclus dans cette étude. Cent huit patients étaient porteurs d'un AVC ischémique (67,9\%), 34 patients étaient porteurs d'un AVC hémorragique (21,4\%) et 17 patients avaient eu un épisode d'ischémie cérébrale transitoire (10,7\%). L'hypertension était le facteur de risque modifiable le plus fréquent $(78,0 \%)$, suivi du diabète (40,3\%) et de la dyslipidémie $(31,5 \%)$. Au moment de la première consultation à la clinique, seulement $26,0 \%$ des patients dyslipidémiques et $64,5 \%$ des patients hypertendus recevaient une médication appropriée. Conclusion : Nous avons observé une prévalence élevée de facteurs de risque modifiables comme l'hypertension chez les patients qui subissent un AVC, ce qui indique qu'on doit favoriser les interventions conventionnelles chez ces patients au Pakistan. Des cliniques spécialisées en AVC et une approche algorithmique en soins primaires pourraient améliorer l'application de stratégies de prévention secondaire fondées sur des preuves dans les pays en voie de développement.

Can. J. Neurol. Sci. 2010; 37: 252-257

Stroke is one of the leading causes of mortality and sustained disability in the developing world. According to World Health Organization estimates, death from stroke in developing countries accounted for $85.5 \%$ of stroke deaths worldwide. ${ }^{1}$ As countries such as Pakistan experience socioeconomic transition and population longevity, this burden is bound to increase. ${ }^{2} \mathrm{~A}$ systematic review of population-based studies of stroke conducted in 2008 shows that the overall stroke incidence in low to middle income countries has exceeded that in high-income countries by $20 \% .^{3}$ In addition, stroke patients in low income countries are a decade younger than their western counterparts and consequently the burden of sustained disability in survivors is greater. ${ }^{4}$

From the Stroke Service (FT, AKK), Section of Neurology, Department of Medicine; Medical College (RZ, URS, MM), Aga Khan University Hospital; Sindh Medical College (SA), Dow University of Health Sciences, Karachi, Pakistan.

Received September 2, 2009. Final Revisions Submitted October 5, 2009. Correspondence to: Ayeesha Kamran Kamal, Section of Neurology, Department of Medicine, Aga Khan University, Stadium Road, PO Box 3500, Karachi, 74300, Pakistan. 
Stroke is a heterogeneous disorder and the distribution of its subtypes and associated risk factors varies by ethnicity and geographical location. ${ }^{5,6}$ An effective strategy to prevent cerebrovascular disease is to elucidate locally relevant risk factors and address them through pharmacological and public health interventions. However, there is a paucity of systematized data on the distribution of stroke subtypes and modifiable risk factors in Pakistani stroke patients. Opportunities for primary and secondary prevention are yet to be recognized and hence, no effective programs are in place. Secondary prevention after cerebrovascular accidents through dedicated stroke clinics has been shown to improve management of modifiable risk factors in developed countries. ${ }^{7,8}$ However, no such reports have been published from the developing world.

This study presents a dedicated stroke clinic experience at a tertiary care hospital in Karachi, Pakistan and describes the distribution of modifiable risk factors in this population.

\section{METHODS}

Study Design and Setting

A systematic retrospective audit of medical records of all patients presenting with an index stroke or transient ischemic attack to a multidisciplinary stroke clinic at a tertiary care hospital in Karachi, Pakistan was conducted. The Section of Neurology at the Aga Khan University Hospital (AKUH) has initiated a specialty stroke clinic run by a certified vascular neurologist for prevention, diagnosis and outpatient management of cerebrovascular disease. This initiative is supported by a multidisciplinary team including a radiologist, a physiotherapist, a nutritionist and a vascular surgeon. The stroke clinic receives referrals from all over Pakistan and from neighboring countries including Afghanistan, Iran, India and United Arab Emirates. Aga Khan University Hospital is an urban tertiary care hospital that runs on a fee-for-service model for healthcare delivery. Nonaffording patients are accommodated through an in-house patient

Table 1: Stroke clinic - Initial assessment form

\begin{tabular}{|c|c|}
\hline Demographics & Disability Assessment \\
\hline Current Age & Modified Rankin Score \\
\hline Gender & NIHSS Score \\
\hline Profession & Barthel Index \\
\hline \multicolumn{2}{|l|}{ Ethnicity } \\
\hline Medical History & Radiological Investigations \\
\hline Age of onset & MRA / MRI Head and/or Neck \\
\hline Duration of symptoms & CT Head \\
\hline Co-morbid Disorders & ECG \\
\hline Prior Stroke History & Echocardiography \\
\hline Current Medications & Carotid Doppler \\
\hline \multicolumn{2}{|l|}{ Substance Abuse } \\
\hline \multicolumn{2}{|l|}{ Smoking } \\
\hline Family History & Laboratory Investigations \\
\hline Stroke & Hemoglobin / Hematocrit \\
\hline Coronary Artery Disease & C Reactive Protein \\
\hline Hypertension & Erythrocyte Sedimentation Rate \\
\hline \multirow[t]{2}{*}{ Diabetes } & Lipid profile \\
\hline & $\mathrm{HbA1C}$ \\
\hline Physical examination & Management \\
\hline Anthropometry & More investigations \\
\hline Vital signs & New medications \\
\hline \multirow{2}{*}{ Neurological Examination } & Lifestyle modifications \\
\hline & Referrals \\
\hline \multicolumn{2}{|l|}{ Neurologic Review } \\
\hline \multicolumn{2}{|l|}{ Depression } \\
\hline \multicolumn{2}{|l|}{ Anhedonia } \\
\hline \multicolumn{2}{|l|}{ Weakness } \\
\hline \multicolumn{2}{|l|}{ Numbness } \\
\hline \multicolumn{2}{|l|}{ Headache } \\
\hline \multicolumn{2}{|l|}{ Diplopia } \\
\hline \multicolumn{2}{|l|}{ Postural instability } \\
\hline \multicolumn{2}{|l|}{ Vertigo } \\
\hline \multicolumn{2}{|l|}{ Memory Loss } \\
\hline \multicolumn{2}{|l|}{ Confusion } \\
\hline Seizures & \\
\hline
\end{tabular}


welfare program.

All patients presenting to the stroke clinic undergo standardized history and physical evaluations, laboratory and radiological investigations, functional scores (National Institutes of Health Stroke Scale (NIHSS), modified Rankin Scale (mRS), Barthel Index and relevant interventions. ${ }^{9-12}$ To ensure a standardized work-up for each patient, an initial and follow-up assessment form has been designed (Table 1).

\section{Patient enrollment and data collection}

Computerized billing records of the AKUH were searched retrospectively to identify all visits to the stroke clinic between September 2006 and August 2008. A list of 403 visits by 218 patients was generated. Medical records of each patient were reviewed. Fifty-nine patients with diagnoses other than stroke or transient ischemic attack (TIA) or with incomplete or missing data were excluded from this study. One hundred and fifty-nine patients met the final inclusion and exclusion criteria. This study was approved by Ethical Review Committee at the AKUH.

Data was collected by three separate data abstractors using a standardized pre-piloted form. These abstractors were final year medical students (RZ, URS and SA) and were trained during a two-day intensive session by the stroke neurologist (AKK). Regular follow-up meetings to address related questions were held during data abstraction.

\section{Variable definitions}

Variables of interest included age, gender, date of event and date of admission to a hospital, type of event and subtype classified according to the TOAST criteria, vascular risk factors, co-morbid diseases, previous medications, results from radiological examinations (e.g. Doppler ultrasound), infarct

Table 2: Distribution of age at first presentation to clinic and gender

\begin{tabular}{llll}
\hline Age & $\begin{array}{l}\text { Male } \\
\mathbf{n}(\%)\end{array}$ & $\begin{array}{c}\text { Female } \\
\mathbf{n}(\%)\end{array}$ & $\begin{array}{l}\text { Total } \\
\mathbf{n}(\%)\end{array}$ \\
\hline$<\mathbf{4 0}$ years & $10(9.8)$ & $9(16.4)$ & $19(12.1)$ \\
$\mathbf{4 0}-\mathbf{4 9}$ years & $15(14.7)$ & $8(14.6)$ & $23(14.7)$ \\
$\mathbf{5 0}-\mathbf{5 9}$ years & $31(30.4)$ & $11(20.0)$ & $42(26.8)$ \\
$\mathbf{6 0}-\mathbf{6 9}$ years & $25(24.5)$ & $14(25.5)$ & $39(24.8)$ \\
$\mathbf{2 7 0}$ years & $21(20.6)$ & $13(23.6)$ & $34(21.7)$ \\
& & & $159(100.0)$ \\
\hline
\end{tabular}

localization, medication for secondary prevention, and severity of the clinical deficit (mRS used at clinic presentation). ${ }^{13}$ Risk factors such as hypertension, diabetes mellitus, smoking, dyslipidemia, coronary artery disease and atrial fibrillation were specifically documented. The following definitions were used:

Diabetes: Fasting blood glucose of $\geq 126 \mathrm{mg} / \mathrm{dL}(7.0$ $\mathrm{mmol} / \mathrm{L}$ ), or symptoms of diabetes plus random blood glucose of $\geq 200 \mathrm{mg} / \mathrm{dL}(11.1 \mathrm{mmol} / \mathrm{L})$, or $2 \mathrm{~h}$ post load glucose of $\geq 200$ $\mathrm{mg} / \mathrm{dL}(11.1 \mathrm{mmol} / \mathrm{L})$ during an Oral Glucose Tolerance Test, or current use of anti-diabetic medications. ${ }^{14}$

Hypertension: Mean of two readings of blood pressure (BP) measurements each at two separate occasions of $\geq 140 \mathrm{mmHg}$ systolic and $\geq 90 \mathrm{mmHg}$ diastolic $\mathrm{BP}$, or current use of antihypertensive medications. ${ }^{15}$

Dyslipidemia: Total serum cholesterol $>200 \mathrm{mg} / \mathrm{dL}(11.1$ $\mathrm{mmol} / \mathrm{L}$ ) or LDL cholesterol > $100 \mathrm{mg} / \mathrm{dL}$ (5.6 mmol/L), or HDL cholesterol $<40 \mathrm{mg} / \mathrm{dL}(2.2 \mathrm{mmol} / \mathrm{L})$, or current use of lipidlowering medications. ${ }^{16}$

Smoking: Quantified in packs (20 cigarettes) per day and duration in years. Defined as ex-smoker if smoking was quit $\geq 6$ months ago.

Transient Ischemic Attack: A transient episode of neurological dysfunction caused by focal brain, spinal cord or retinal ischemia without acute infarction. ${ }^{17}$

\section{Data Entry and Analysis}

Data was entered and analyzed using SPSS 14.0 (SPSS, Chicago, IL, USA). Descriptive statistics including percentages, means and standard deviations have been reported as appropriate. Chi-square $\left(\chi^{2}\right)$ test for categorical variables and Student's t test for continuous variables were used to compare differences between groups. P-values less than 0.05 were considered significant.

\section{Results}

A total of 159 patients were included in this audit with 104 males $(65.4 \%$; mean age \pm SD: $57.3 \pm 12.9$ years) and 55 females (34.6\%; mean age \pm SD: $56.7 \pm 15.5$ years). There was no significant difference in mean age of males and females. Distribution of patients across age groups and gender is shown in Table 2.

Ischemic stroke was seen in 108 patients (67.9\%), while 34 patients $(21.4 \%)$ were diagnosed with hemorrhagic stroke and 17 patients $(10.7 \%)$ with TIA. Most common cause of ischemic stroke was large artery atherosclerosis seen in 46 patients $(28.9 \%)$.

Hypertension was the most prevalent risk factor present in $78 \%(n=124)$ of the population, followed by diabetes in $40.3 \%$ $(n=64)$, dyslipidemia in $31 \%(n=50)$ and smoking in $21 \%$ $(n=33)$. The distribution of risk factors across stroke subtypes is presented in Table 3. With the exception of atrial fibrillation and its association with cardioembolic stroke $(p=0.001)$, the distribution of other risk factors did not vary significantly. Diabetes and hypertension were observed most commonly in patients with lacunar stroke. In contrast, smoking was most commonly observed in the large artery atherosclerosis subgroup and dyslipidemia was most commonly seen in the cardioembolic stroke subgroup. 
Table 3: Distribution of risk factors among types of stroke

\begin{tabular}{|c|c|c|c|c|c|c|}
\hline Risk Factors & $\begin{array}{l}\text { ICH }(n=34) \\
n(\%)\end{array}$ & $\begin{array}{l}\text { Large artery } \\
(n=46) \\
n(\%)\end{array}$ & $\begin{array}{l}\text { Lacunar } \\
(n=39) \\
n(\%)\end{array}$ & $\begin{array}{l}\text { Cardioembolic } \\
(n=19) \\
n(\%)\end{array}$ & $\begin{array}{l}\text { Total }^{2} \\
(n=159) \\
n(\%)\end{array}$ & p-value \\
\hline Hypertension & $28(82.4)$ & $35(76.1)$ & $33(84.6)$ & $13(68.4)$ & $124(78.0)$ & 0.478 \\
\hline DM & $10(29.4)$ & $19(41.3)$ & $21(53.9)$ & $6(31.6)$ & $64(40.3)$ & 0.154 \\
\hline Smoking & $4(11.8)$ & $14(30.4)$ & $5(12.8)$ & $4(21.1)$ & $33(20.8)$ & 0.115 \\
\hline Atrial fibrillation & $3(8.8)$ & $3(6.5)$ & $0(0.0)$ & $6(31.6)$ & $12(7.6)$ & 0.001 \\
\hline Dyslipidemia $^{1}$ & $11(32.4)$ & $16(34.8)$ & $13(33.3)$ & $8(42.1)$ & $50(31.5)$ & 0.902 \\
\hline
\end{tabular}

${ }^{1}$ Total cholesterol > $200 \mathrm{mg} / \mathrm{dL}(11.1 \mathrm{mmol} / \mathrm{L}), \mathrm{LDL}>100 \mathrm{mg} / \mathrm{dL}(5.6 \mathrm{mmol} / \mathrm{L}), \mathrm{HDL}<40 \mathrm{mg} / \mathrm{dL}(2.2 \mathrm{mmol} / \mathrm{L})$.

${ }^{2}$ Total number of patients $(\mathrm{n}=159)$ also includes patients with Transient Ischemic Attacks $(\mathrm{n}=17)$ not shown in this table.

ICH - Intracranial Hemorrhage

Pharmacological interventions made at this stroke clinic included anti-hypertensive, anti-thrombotic, lipid-lowering, antidepressant, anti-diabetic and other clinically indicated medications. The Figure shows the proportion of patients taking anti-hypertensive, anti-thrombotic or lipid-lowering medication before and after their initial stroke clinic visit. The difference between proportions of patients taking specific medications before and after their visit to this clinic reflects the number of patients in whom such medications were clinically indicated for secondary prevention but were never prescribed. Lipid-lowering drugs were the most common medications prescribed to 74 patients $(46.5 \%)$ for the first time. At presentation to the stroke clinic, $26.0 \%$ patients $(n=13)$ with dyslipidemia were taking lipid-lowering medications and this proportion increased to $78.0 \%(n=39)$ following their visit. Similarly, $64.5 \%$ of hypertensive patients $(\mathrm{n}=80)$ were on any kind of antihypertensive medications and this proportion increased to $94.4 \%$ $(\mathrm{n}=117)$ following their visit. Among patients already on antihypertensives prior to their visit, only $54.4 \%(n=43)$ of patients had adequately controlled blood pressures. Of patients with ischemic stroke or TIA $(n=59), 47.2 \%$ were already on antithrombotic or anti-platelet medications and this proportion increased to $90.4 \%(\mathrm{n}=113)$ following their initial visit.

Most patients $(57.0 \%, \mathrm{n}=61)$ had no significant disability with an mRS less than 1 while $19.6 \%(n=21)$ had moderately severe disability with an $\mathrm{mRS}$ of 5 . One hundred and forty six patients $(91.8 \%)$ underwent neuroimaging using either cranial computed tomogram (CT) scans (68 patients) or cranial magnetic resonance imaging (MRI) scans (77 patients). The magnetic resonance angiogram (MRA) was carried out in 46 patients and carotid Doppler ultrasound was carried out in 29 patients. Patients with more than $70 \%$ stenosis on carotid Doppler were referred to the vascular surgeon for carotid endarterectomy.

\section{DISCUSSION}

This study reports the distribution of stroke subtypes and modifiable risk factors and the outcomes of a standardized evidence-based algorithmic approach of investigation and treatment at a dedicated stroke clinic in a developing country.

Patients in this clinical sample have a younger mean age as compared to their counterparts in the developed world. About $56 \%$ of patients were below the age of 60 years. In contrast, the Framingham Heart Study reports a mean age of 75.1 years for women and 71.1 years for men presenting with first incident stroke. ${ }^{18}$ About $65 \%$ of our patients were males. Communitybased studies indicate that stroke is more common in men than in women globally. ${ }^{19}$ In the absence of local epidemiological evidence, we may speculate that gender disparity in our sample is due to under reporting of female patients or an actual lower prevalence of stroke in women. However, community based studies are required to evaluate the average age and gender distribution of stroke adequately.

Hypertension was the most prevalent modifiable risk factor in our sample. Adequate control of hypertension minimizes the risk of subsequent stroke particularly intracranial hemorrhage, large artery stenosis and lacunes. The large decline in mortality in ageadjusted stroke and coronary artery disease in Western countries has been attributed to widespread and improved control of hypertension. ${ }^{20}$ Lin et al have demonstrated the effectiveness of 


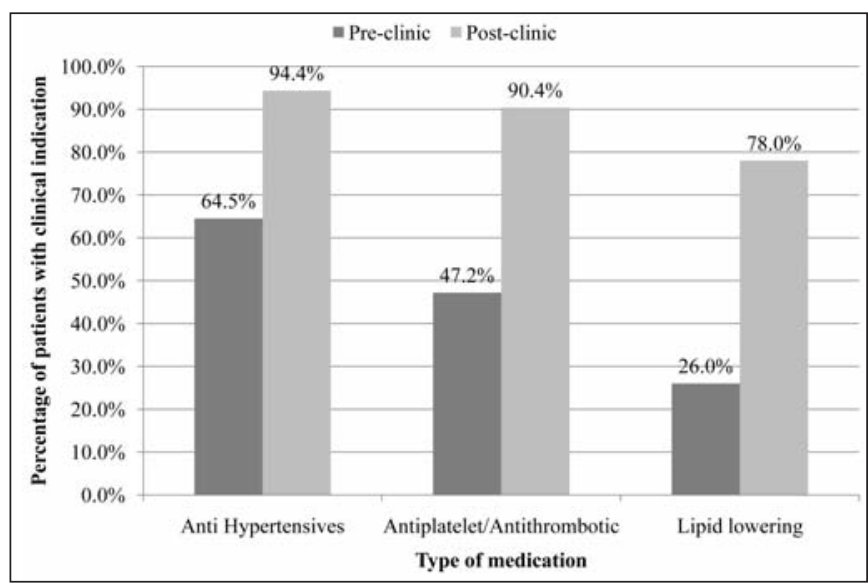

Figure: Comparison of anti-hypertensive, anti-platelet and lipidlowering medications taken by patients before and after their visit to the stroke clinic. Percentages have been calculated using subgroups of patients with clinical indication for relevant medications. Therefore, the difference in percentage before and after clinic accounts for patients with no pharmacotherapy despite clinical indication. community-based hypertension control programs in reducing stroke mortality in Taiwan. Between 1994 and 1997, stroke mortality rate decreased by $39.9 \%$ and $4.8 \%$ in the intervention and reference communities respectively. ${ }^{21}$ Similarly, prior use of lipid-lowering statins has been shown to improve outcomes after stroke in observational studies. ${ }^{22}$ However, pharmacotherapy for hypertension and dyslipidemia was inadequate in most patients prior to their initial clinic visit in our sample. About $65 \%$ hypertensive patients were on appropriate medications and only $54 \%$ of this subset were adequately controlled while a meager $20 \%$ of all patients were taking statins. In contrast to western vascular neurology clinics, interventions in our setting relied on implementation of conventional wisdoms for prevention that were frequently missed at the primary care level. Rarely did complex vascular cases come up for intervention.

Limitations of our study include its reliance on clinical data from a single urban tertiary care center in a fee-for-service system. While non-affording patients are regularly accommodated through patient welfare, our sample may not be entirely representative of stroke patients in Pakistan. Hence, distribution of stroke subtypes or risk factors cannot be generalized to the entire Pakistani population. Nevertheless, this clinical study has adequately demonstrated the lack of secondary prevention measures in patients with stroke prior to their index clinic visit. A standardized algorithm was used for each patient and detailed investigations were sought whenever possible and this approach helped identify inadequate secondary interventions.

\section{Conclusions}

A wide prevalence of potentially modifiable risk factors such as hypertension amongst stroke patients has been observed in our study. Pragmatic entry points for primary and secondary prevention of stroke in Pakistan have been identified. Specialty services dealing with stroke in such developing countries may benefit from adaptation of a similar evidence-based algorithmic approach to investigations and treatment in order to maximize secondary prevention. In primary care, similar systematic screening for prevalent and amenable risk factors will help decrease the burden of cerebrovascular disease in the community.

\section{COMPETING INTERESTS}

AKK is the director of Stroke Service at Aga Khan University Hospital and runs the Stroke Clinic.

\section{Author Contributions}

FT and AKK conceived the idea and designed the study. RZ, URG and SA collected the data. MM, RZ and AKK analyzed the data and wrote the manuscript. All authors read and approved the final version.

\section{ACKNOWLEDGEMENTS}

The authors thank the following people for supporting the Stroke Clinic: Dr. Fawzia Shah, Haroon Daniel, Arshad Warwani, Munira Punjwani, Dr. Ziad Sophie, Dr. M. Wasay, Dr. Azeemuddin, Dr. Waqar Kashif, Dr. Abdul Wajid.

\section{REFERENCES}

1. Feigin VL. Stroke in developing countries: can the epidemic be stopped and outcomes improved? Lancet Neurol. [Reflection and Reaction]. 2007 Feb;6(2):94-7.

2. Omran AR. The epidemiologic transition. A theory of the epidemiology of population change. Milbank Mem Fund Q. 1971 Oct;49(4):509-38

3. Feigin VL, Lawes CM, Bennett DA, Barker-Collo SL, Parag V. Worldwide stroke incidence and early case fatality reported in 56 population-based studies: a systematic review. Lancet Neurol. 2009 Apr;8(4):355-69.

4. Truelsen T, Heuschmann P, Bonita R, Arjundas G, Dalal P, Damasceno A, et al. Standard method for developing stroke registers in low-income and middle-income countries: experiences from a feasibility study of a stepwise approach to stroke surveillance (STEPS Stroke). Lancet Neurol. 2007 Feb;6 (2):134-9.

5. Moussouttas M, Aguilar L, Fuentes K, Anyanwu B, Manassarians $\mathrm{H}$, Papamitsakis $\mathrm{N}$, et al. Cerebrovascular disease among patients from the Indian subcontinent. Neurology. 2006 Sep 12; 67(5):894-6.

6. Feigin VL LC, Bennett DA, Anderson CS. Stroke epidemiology: a review of population-based studies of incidence, prevalence, and case-fatality in the late 20th century. Lancet Neurol. [Review]. 2003 Jan;2(1):43-53.

7. Lin Y, Li YS, Xu Q, Shi GW, Li HW, Geng JL. [The impact of stroke clinic on improving the compliance with the guidelines for secondary prevention of ischemic stroke]. Zhonghua Nei Ke Za Zhi. 2007 Sep;46(9):736-9.

8. Mouradian MS, Hussain MS, Lari H, Salam A, Senthilselvan A, Dean $\mathrm{N}$, et al. The impact of a stroke prevention clinic in diagnosing modifiable risk factors for stroke. Can J Neurol Sci. 2005 Nov;32(4):496-500.

9. Bonita R, Beaglehole R. Recovery of motor function after stroke. Stroke. 1988 Dec;19(12):1497-500.

10. Brott T, Adams HP, Jr., Olinger CP, Marler JR, Barsan WG, Biller $\mathrm{J}$, et al. Measurements of acute cerebral infarction: a clinical examination scale. Stroke. 1989 Jul;20(7):864-70.

11. Rankin J. Cerebral vascular accidents in patients over the age of 60 . II. Prognosis. Scott Med J. 1957 May;2(5):200-15. 
12. Wade DT, Collin C. The Barthel ADL Index: a standard measure of physical disability? Int Disabil Stud. 1988;10(2):64-7.

13. Adams HP, Jr., Bendixen BH, Kappelle LJ, Biller J, Love BB, Gordon DL, et al. Classification of subtype of acute ischemic stroke. Definitions for use in a multicenter clinical trial. TOAST. Trial of Org 10172 in Acute Stroke Treatment. Stroke. 1993 Jan; 24(1):35-41.

14. Diagnosis and classification of diabetes mellitus. American Diabetes Association. Diabetes Care. 2006 Jan;29 Suppl 1: S43-8.

15. Chobanian AV, Bakris GL, Black HR, Cushman WC, Green LA, Izzo JL, Jr., et al. The Seventh Report of the Joint National Committee on Prevention, Detection, Evaluation, and Treatment of High Blood Pressure: the JNC 7 report. JAMA. 2003 May 21; 289(19):2560-72.

16. Executive Summary of The Third Report of The National Cholesterol Education Program (NCEP) Expert Panel on Detection, Evaluation, And Treatment of High Blood Cholesterol In Adults (Adult Treatment Panel III). JAMA. 2001 May 16;285(19):2486-97.

17. Brown MM, Rudd A, McGovern R. Transient ischemic attack-proposed new definition. N Engl J Med. 2003 Apr 17;348(16): 1607-9; author reply -9 .
18. Petrea RE, Beiser AS, Seshadri S, Kelly-Hayes M, Kase CS, Wolf PA. Gender Differences in Stroke Incidence and Poststroke Disability in the Framingham Heart Study. Stroke. 2009 Apr;40 (4)1032-7.

19. Appelros P, Stegmayr B, Terent A. Sex differences in stroke epidemiology: a systematic review. Stroke. 2009 Apr;40(4): 1082-90.

20. Jacobs DR, Jr., McGovern PG, Blackburn H. The US decline in stroke mortality: what does ecological analysis tell us? Am J Public Health. 1992 Dec;82(12):1596-9.

21. Lin T, Chen CH, Chou P. Impact of the high-risk and mass strategies on hypertension control and stroke mortality in primary health care. J Hum Hypertens. 2004 Feb;18(2):97-105.

22. Amarenco P, Labreuche J. Lipid management in the prevention of stroke: review and updated meta-analysis of statins for stroke prevention. Lancet Neurol. 2009 May;8(5):453-63. 